\title{
CONTEXT-AWARE SYSTEM BERBASIS RFID UNTUK MONITORING PENDERITA AUTISME
}

\author{
Ratna Aisuwarya \\ Jurusan Sistem Komputer Fakultas Teknologi Informasi \\ Universitas Andalas \\ Jl. Kampus Unand Limau Manis Padang 25163 \\ aisuwarya@fmipa.unand.ac.id
}

\begin{abstract}
Abstrak
Penderita autisme atau biasa disingkat autis pada umumnya membutuhkan pegawasan setiap harinya agar kebutuhan penderita dapat dipenuhi. Ada beberapa resiko yang mungkin timbul jika pengawas atau penghuni rumah terlambat mengetahui keberadaan penderita. Penelitian ini dilakukan untuk mengimplementasikan teknologi RFID sebagai tag penanda yang dipasang pada lengan penderita autis. Setiap tag yang terbaca oleh Reader pada tiap lokasi akan dijadikan input pada sistem untuk menentukan karateristik situasi pada lokasi tertentu (ContexAware). Penelitian ini menggunakan kategori contexttriggered action, karena sistem diharapkan dapat bereaksi secara otomatis berdasarkan context yang ada dan terdeteksi. Mekanisme inferensi menggunakan aturan IF-THEN. Implementasi disain sistem yang telah dirancang dengan meletakan reader RFID di masing-masing pintu pembatas ruangan rumah. Dalam penelitian ini akan digunakan 4 ruangan sebagai simulasi, yaitu: kamar tidur, dapur, ruang tengah, dan kamar mandi dengan asumsikan penderita autis tidak melakukan aktivitas di luar ruangan rumah seperti teras atau pekarangan. Karena keterbatasan pada implementasi sistem, komputer digunakan sebagai penampil dan pengolah data lokasi tag melewati sebuah RFID reader. Hasil pengujian menunjukan bahwa lokasi penderita dapat ditentukan berdasarkan hasil pembacaan reader RFID dengan tingkat keberhasilan dari 10 kali pengujian sebesar $70 \%$.
\end{abstract}

Kata kunci: Context-aware, RFID, Arduino, Autisme

Abstract
Autism or commonly abbreviated as autis generally
require supervise every day so that the needs of
patients are met. There are some risks that may arise
if the supervisor or the occupants of the house late

know the whereabouts of the patient. This research was done to implement RFID technology as a tag put on the arm of an autis. Each tag is read by a reader at each location that later will be used as input to the system to determine the characteristics of the situation at a particular location (Contex-Aware). This research uses a context-triggered action category, because the system is expected to react automatically based on the existing context that are detected. IF-THEN rules are used for inference mechanism. Design implementation system has been applied by locating RFID reader at each door of the house room. In this reseach, four rooms will be used as a simulation, namely: a bedroom, kitchen, living room, and a bathroom with autistic patients do not assume doing an outdoor activity such as a terrace house or yard. Due to limitations in the implementation of the system, the computer is used as a viewer and data processor locations RFID tag passes through a reader. The test results showed that the location of the patient can be determined based on the reading of RFID reader with a success rate of 10 times testing by $70 \%$.

Keywords: Context-aware, RFID, Arduino, Autism

\section{Pendahuluan}

Autisme adalah kelainan perkembangan sistem saraf pada seseorang yang kebanyakan diakibatkan oleh faktor hereditas (Maljaars, Boonen, Lambrechts, Van Leeuwen, \& Noens, 2014). Karakteristik yang menonjol pada seseorang yang mengidap kelainan ini adalah kesulitan membina hubungan sosial, berkomunikasi secara normal maupun memahami emosi serta perasaan orang lain. Dikatakan oleh para ahli bahwa anak-anak dengan autisme dengan tingkat intelegensi dan kognitif yang rendah, tidak berbicara (nonverbal), memiliki perilaku menyakiti diri sendiri, 
serta menunjukkan sangat terbatasnya minat dan rutinitas yang dilakukan maka mereka diklasifikasikan sebagai low functioning autism. Sementara mereka yang menunjukkan fungsi kognitif dan intelegensi yang tinggi, mampu menggunakan bahasa dan bicaranya secara efektif serta menunjukkan kemampuan mengikuti rutinitas yang umum diklasifikasikan sebagai high functioning autism (Ratajczak, 2011). Dua dikotomi dari karakteristik gangguan sesungguhnya akan sangat berpengaruh pada perilaku sehari-hari penderita autis di lingkungan rumah. Seringkali aktivitas penderita autis cenderung membahayakan diri mereka sendiri, atau anggota keluarga lainnya. Sehingga diperlukan langkah-langkah preventif yang dapat dilakukan untuk mengantisipasi hal tersebut agar tidak terjadi.

Penderita autis ringan dan sedang umumnya masih tetap bertempat tinggal di rumah keluarga mereka. Harus dilakukan pengawasan setiap harinya agar kebutuhan penderita dapat dipenuhi. Tetapi, keluarga penderita mungkin saja luput mengawasi penderita saat malam hari. Kebanyakan penderita memiliki gangguan tidur pada malam hari. Mereka cenderung memiliki aktifitas di malam hari seperti, berjalan-jalan, mengambil barang dan lain-lain. Aktivitas-aktivitas ini dapat membahayakan penghuni rumah, karena bisa saja penderita tidak sadar melakukan aktifitas yang beresiko seperti, menghidupkan kompor gas atau membuka pintu rumah.

Kini dengan kemajuan teknologi rumah bisa menjadi lebih nyaman dan menyenangkan bagi penderita autis dan keluarga yang tinggal bersamanya. Rumah yang dilengkapi dengan teknologi ini biasa dikenal dengan smart home (rumah cerdas). Teknologi smart home umumnya terbatas pada pengontrolan dan hak akses perangkat rumah tangga. Untuk pemantauan penderita autis tersebut perlu sebuah sistem yang dapat memberikan notifikasi keberadaan user yang dalam hal ini adalah penderita autis.

Penelitian ini mengimplementasikan teknologi RFID sebagai tag penanda pada penderita autis. Setiap tag yang terbaca oleh reader pada tiap lokasi akan dijadikan input pada sistem untuk menentukan karateristik situasi pada lokasi tertentu (ContexAware). Penelitian terkait dengan pemanfaatan RFID dalam pendeteksian lokasi keberadaan objek di dalam ruangan telah dilakukan oleh (Ting, Kwok, Tsang, \& Ho, 2011). Penelitian ini menggunakan tag pasif sebagai penanda lokasi objek. Hasil penelitian menunjukkan bahwa pembacaan tag RFID pasif dapat digunakan untuk sistem pendeteksian posisi, dan sistem ini dapat menjadi solusi yang efektif jika dibandingkan dengan teknologi pendeteksian posisi lainnya.

Berdasarkan hal tersebut, maka pada penelitian ini akan diimplementasikan teknologi RFID dengan tag pasif sebagai input sistem monitoring penderita autisme. Sehingga diharapkan dengan adanya penelitian ini dapat membantu keluarga atau pihak yang bertugas mengawasi penderita autis dalam kesehariannya. Terutama saat dimana pengawasan terhadap penderita minim, seperti di malam hari. Dengan adanya penanda pada tiap-tiap lokasi, notifikasi yang diberikan sebagai output sistem dapat menjadi indikator untuk melakukan langkah-langkah preventif bagi keluarga dan pengawas yang ditugaskan.

\section{KAJIAN LITERATUR}

\section{II.1 Context-Aware System}

Context-aware mengacu pada kemampuan perangkat komputer untuk mendeteksi, merespon, dan berinteraksi dengan user (Maynord, 2014). Selain itu dapat juga diartikan sebagai sebuah aplikasi yang secara dinamis berubah atau beradaptasi berdasarkan context antara user dan aplikasi. Context sebagai informasi yang menggambarkan situasi dari sebuah entitas seperti orang, tempat, atau objek yang dianggap relevan terhadap interaksi antara user dan aplikasi tersebut.

Context dapat dikategorikan ke dalam 4 tipe, yaitu lokasi (location), identitas (identity), waktu (time), dan entitas (entity) (Rivero-Rodriguez, Pileggi, \& Nykänen, 2016). Location sebagai representasi lokasi user atau lokasi sebuah identity. Identity sebuah context sebagai penanda dengan siapa sistem berkomunikasi. Ketika user memasuki wilayah servis dan servis tersebut tersedia bagi user pada saat itu, maka context yang digunakan adalah time. Tipe yang terakhir adalah entity, sebagai repesentasi informasi tentang segala hal yang digunakan oleh user.

Suatu sistem dapat dikatakan sebagai contexaware, jika sistem tersebut memonitor input dan secara otomatis menyediakan informasi dan atau bereaksi sesuai dengan context yang dilakukan oleh user sesuai dengan hasil masukan input (Dey \& Abowd, 1999). Reaksi yang dihasilkan dapat berupa 
menampilkan informasi kepada user, eksekusi program berdasarkan context, atau konfigurasi tampilan grafis berdasarkan context. Sistem yang menggunakan konsep context-aware melibatkan pengambilan informasi dari lingkungan user sebagai penentu alur pengambilan keputusan pada program yang dinamis berdasarkan context yang ada.

\section{II.2 Autisme}

Secara etimologis kata "autisme" diartikan sebagai suatu paham yang hanya tertarik pada dunianya sendiri. Perilakunya timbul semata-mata karena dorongan dari dalam dirinya sendiri. Penyandang autisme seakan-akan tidak peduli dengan stimulus-stimulus yang datang dari orang lain. Menurut (Maljaars et al., 2014) menjelaskan bahwa autistik adalah gangguan perkembangan neurobiologis berat yang mempengaruhi cara seseorang untuk berkomunikasi dan berelasi (berhubungan) dengan orang lain. Autisme merupakan salah satu gangguan perkembangan yang merupakan bagian dari Kelainan Spektrum Autisme atau Autism Spectrum Disorders (ASD) dan juga merupakan salah satu dari lima jenis gangguan dibawah payung Gangguan Perkembangan Pervasif atau Pervasive Development Disorder (PDD) (Ratajczak, 2011).

\section{II.3 Radio Frequency Indentification (RFID)}

RFID merupakan sebuah sistem identifikasi objek atau benda menggunakan transmisi frekuensi radio untuk menyimpan atau mengambil data jarak jauh (Teicholz \& Williams, 2013). Teknologi ini mampu mengidentifikasi berbagai objek secara simultan tanpa di perlukan kontak langsung atau jalur cahaya untuk berkomunikasi.

Pada dasarnya RFID terdiri dari 3 komponen seperti yang terlihat pada gambar 1 yaitu:

1. Antenna atau koil

2. Penerima (transceiver) dengan decoder

3. Pengirim (transponder) berupa RF tag yang telah deprogram secara elektronik dengan informasi unik
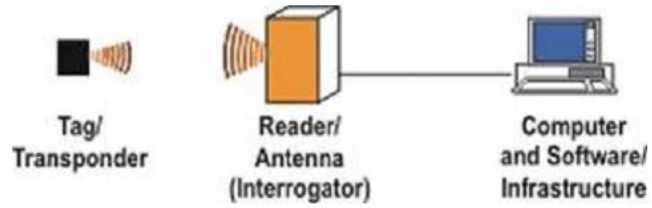

Gambar 1. Reader RFID
Adapun komponen-komponen sebuah modul RFID dengan skala prototype seperti pada gambar terdiri dari :

\section{Tag RFID}

RFID tag adalah sebuah divais pembawa data yang terbuat dari silikon chip dilengkapi sebuah radio antena kecil (Helmeste, 2016). ID yang dibawa RFID tag dapat dibaca pada jarak yang cukup jauh tergantung dari jenis tag yang digunakan. Secara umum, tag dapat diklasifikasikan sebagai aktif dan pasif (Khan, Sharma, \& Prabhu, 2009). Tag pasif tidak memiliki sumber daya on-board. Tag ini mendapatkan daya dari sinyal Continous Wave (CW) yang dikirimkan oleh reader untuk mengoperasikan chip. Sehingga, tag ini berukuran lebih kecil. Tag aktif memiliki sumber daya on-board yang digunakan untuk mengirimkan data dari tag ke reader, dan daya ini juga merupakan sumber daya komponen elektronik lainnya yang terpasang pada tag tersebut.

\section{Reader RFID}

Reader RFID adalah sebuah alat scanning yang dapat membaca tag dengan benar dan mengkomunikasikan hasilnya ke suatu database yang ada. Reader RFID terdiri dari rfid-reader ID-12 (Emulation, 2010) dan modul reader seperti terlhat pada gambar 2 berikut.

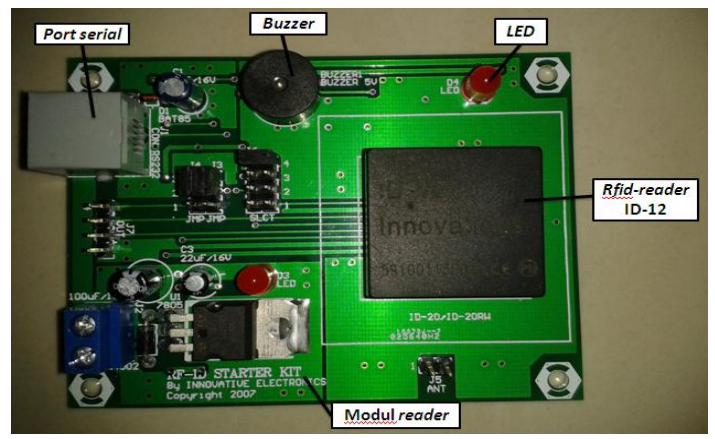

Gambar 2. Modul Reader RFID

Di dalam RFID-reader ID-12 terdapat antena internal yang akan mempengaruhi jarak optimal identifikasi. Pada reader dan tag masing masing memiliki antena yang berbentuk lilitan. Apabila antenna tag dan reader di dekatkan maka akan menghasilkan energy, selanjutnya energy ini diubah menjadi bentuk listrik pada antena. Antena reader merasakan perubahan energy ini dan mengkonversi perubahannya menjadi nilai digital yang dapat di 
mengerti oleh komputer. Selanjutnya reader akan mengirimkan energi yang dihasilkan dari proses transmisi tadi untuk mengambil data yang dibawa tag. Kemudian data tersebut diteruskan reader ke database aplikasi (Emulation, 2010).

\section{AnAlisis dan Perancangan}

\section{III.1 Alat dan Bahan}

Sistem yang telah dirancang didesain dengan menggunakan alat dan bahan sebagai berikut :

\section{Perangkat Keras (Hardware)}

Modul RFID starter kit sebagai reader dan tag RFID pasif. Modul RFID kemudian dihubungkan dengan mikrokontroler tipe Arduino Mega. Data serial hasil pembacaan tag yang diterima oleh RFID reader kemudian diteruskan oleh mikrokontroler ke PC. Informasi yang telah diproses berupa informasi lokasi user yang terbaca pada sistem akan ditampilkan. Disain sistem seperti pada gambar 3.

\section{Perangkat Lunak (Software)}

Software yang digunakan pada implementasi penelitian ini berupa : Arduino IDE sebagai software yang digunakan untuk memprogram Mikrokontroler Arduino untuk antar muka dengan modul RFID, dan Microsoft Visual Studio 2008 development berbasis bahasa pemrograman C. Program yang dibuat berupa aplikasi penentuan lokasi user yang nantinya ditampilkan informasi tersebut pada layar PC.

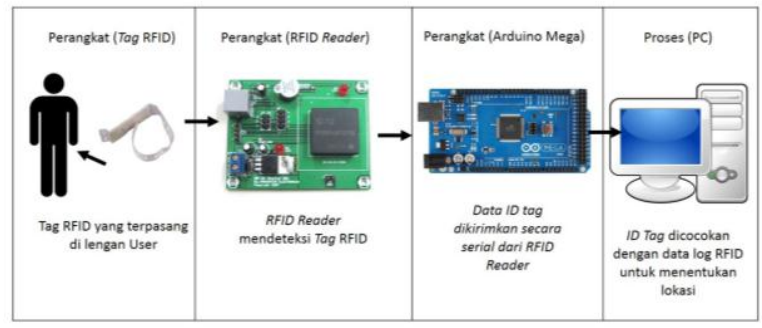

Gambar. 3 Modul Reader RFID

\section{III.2 Prosedur}

Skenario sistem yang dirancang seperti pada Gambar 4, dapat dijelaskan sebagai berikut :

1. RFID Reader dipasang pada lokasi yang telah ditentukan (pembatas pintu 4 ruangan sebagai simulasi, yaitu : kamar tidur, dapur, ruang tengah, dan kamar mandi).
2. Setiap RFID Reader memiliki informasi lokasi ruangan sebagai ID ruangan.

3. Tag pasif dipasang pada lengan user (penderita autis).

4. Tag yang terbaca akan diverifikasi sesuai data yang tersimpan pada data log RFID. Sehingga, tag lain selain itu tidak akan dikenali oleh reader.

5. Ketika user melewati suatu ruangan, maka lokasi tersebut akan di cek pada data kolom informasi lokasi. Informasi tag, lokasi ruangan yang dilewati oleh user, serta waktu pembacaan akan disimpan pada data log.

6. Informasi lokasi tersebut juga akan ditampilkan pada display monitor PC.

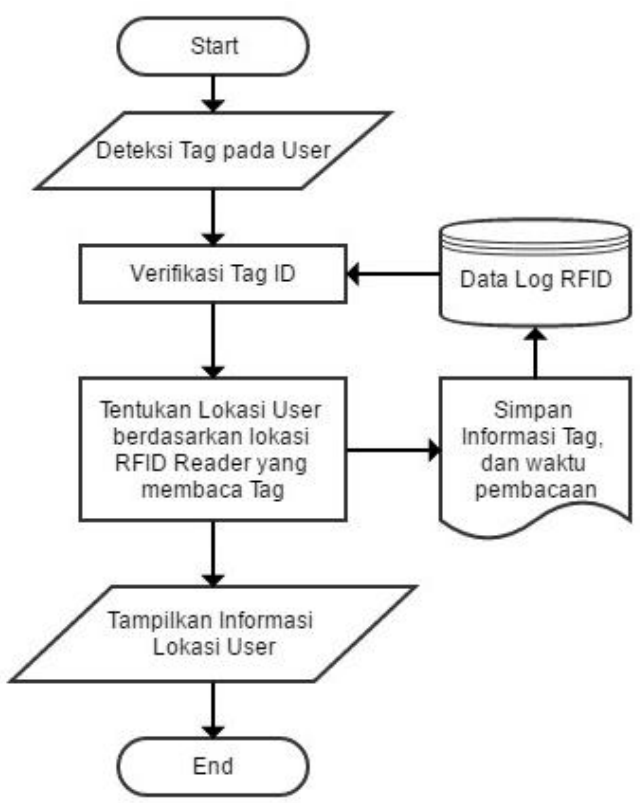

Gambar 4. Flowchart Identifikasi Lokasi

\section{III.3 Kategori Context-Aware}

Penelitian ini menggunakan kategori contexttriggered action, karena sistem diharapkan dapat bereaksi secara otomatis berdasarkan context yang ada dan terdeteksi. Sesuai dengan tujuan perancangan sistem monitoring penderita autisme, sistem diharapkan dapat memberikan suatu informasi mengenai keberadaan user. Sehingga, pemilihan kategori context-aware berbasis pada context- 
triggered action. Mekanisme inferensi menggunakan aturan IF-THEN sebagai berikut :

IF $<$ context $1>$

AND<context2>

$\cdots$.

AND $<$ context(n)>

THEN<display_notification(i)>

Sebagai contoh, terjadi skenario sesuai dengan context berikut :

Waktu = '04.00 PM'

$\mathrm{ID}=$ '110008368DA2'

Lokasi $=$ 'Dapur'

Maka rule yang akan diimplementasikan adalah sebagai berikut :

IF Waktu $=04.00 \mathrm{PM}$

AND ampm $=$ 'pm'

AND lokasi $=$ 'Dapur'

THEN tampilkan_notifikasi $=$ "Pasien berada di dapur, cek persediaan makanan"

\section{III.4 Pengujian Perangkat}

Pengujian perangkat perlu dilakukan agar sistem yang telah dirancang dapat berjalan sesuai dengan hasil yang diharapkan. Terdapat tiga jenis pengujian yang akan dilakukan, yaitu:

1. Pengujian jarak jangkauan pembacaan reader RFID. Pengujian ini dilakukan dengan cara pengukuran rentang baca reader dari berbagai arah yaitu : arah depan, arah belakang, arah kiri, arah kanan, serta posisi di bawah reader.

2. Pengujian komunikasi serial antara reader RFID dengan mikrokontroler dan PC. Kedua, dilakukan pengujian komunikasi serial antara RFID dengan komputer host. Yang akan diujikan menggunakan serial monitor pada software arduino dan hyperterminal pada komputer host Pertama pengujian dilakukan dengan cara menyambungkan perangkat $R F I D$ reader dengan power supply tegangan 12 volt, jika led pada reader menyala ini menandakan bahwa perangkat RFID sudah aktif. Pada reader RFID sudah di lengkapi led dan buzzer. Dimana led sebagai indicator tulis dan buzzer sebagai indicator baca. Bunyi dari buzzer dan led menyala menandakan bahwa proses identifikasi berhasil dilakukan.
Selanjutnya supaya data dari tag yang di baca oleh reader terbaca di PC maka reader ini harus terhubung ke PC dengan cara menghubungkan kabel USB yang terdapat pada reader ke komputer atau laptop. Setelah driver disambungkan, nomor port comm akan dapat dikenali sistem operasi. dan operasi pembacaan tag oleh reader dapat dilakukan. Selanjutnya jalankan software hyperterminal untuk melihat kode yang tertanam di dalam tag.

\section{III.5 Pengujian Identifikasi Tag pada User}

RFID Reader yang terpasang di beberapa lokasi yang dirancang diharapkan dapat mengidentifikasi tag yang ada pada lengan user. Sehingga perlu dilakukan pengujian apakah RFID reader mampu membaca tag yang terpasang di lengan penderita autisme (seperti terlihat pada gambar 6) saat berjalan melintasi suatu ruangan yang telah ditandai.

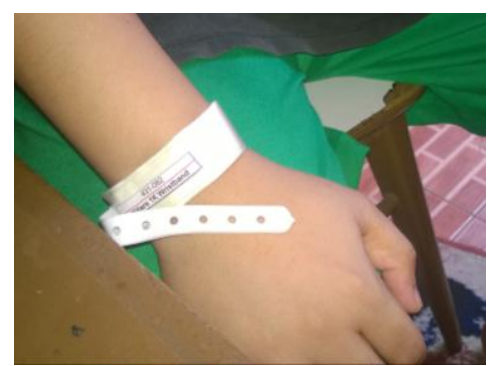

Gambar 6. Pemasangan Tag pada Lengan Penderita Autisme

Pengujian dilakukan dengan cara menyalakan perangkat $R F I D$ reader dengan $\mathrm{PC}$, selanjutnya reader akan membaca tag ketika posisi tag sejajar atau berada pada range baca dari RFID reader. Karena reader yang digunakan frekuensi kerjanya rendah (125 Khz) maka tag yang berada pada lengan user yang discan harus berada dekat dengan reader selanjutnya jalankan perangkat lunak aplikasi. Gambar 7 memperlihatkan proses pembacaan tag oleh RFID reader yang terpasang di depan pintu suatu ruangan.

\section{III.6 Pengujian pembacaan Tag User}

Pengujian ini dilakukan dengan melihat hasil proses identifikasi lokasi user. Tag yang terpasang di tangan user akan dideteksi oleh Reader RFID. Tag yang terbaca akan diverifikasi sesuai data yang tersimpan pada data log RFID. Proses identifikasi lokasi dikatakan berhasil jika ketika user melewati suatu ruangan, maka data lokasi yang ditampilkan pada layar monitor PC sesuai dengan informasi lokasi 
yang sesungguhnya. Hasil pengujian identifikasi pembacaan tag terlihat dari Tabel 1.

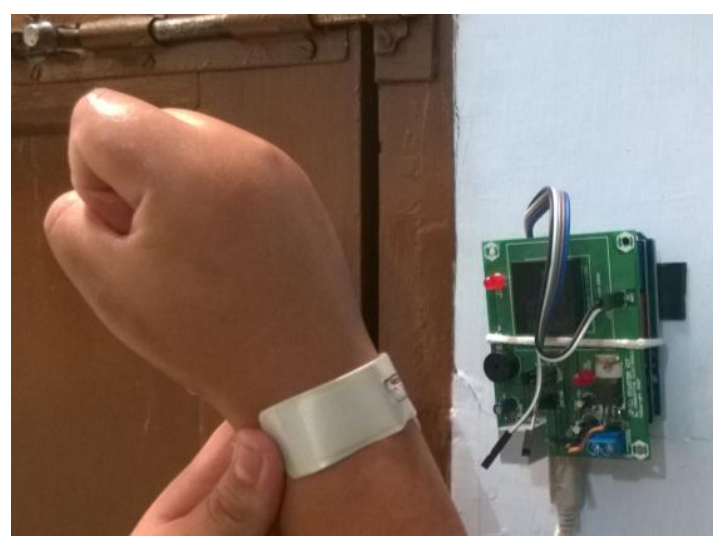

Gambar 7. Pembacaan Tag oleh RFID Reader

Tabel 1. Hasil Identifikasi Lokasi Tag RFID

\begin{tabular}{cccc}
\hline \hline No. & ID Tag & Ket. & Informasi \\
\hline \hline 1 & $110008368 \mathrm{DA} 2$ & Terbaca & Dapur \\
2 & $1100080 \mathrm{AA} 3 \mathrm{~B} 0$ & Terbaca & Dapur \\
3 & $1100083 \mathrm{~A} 1 \mathrm{C} 3 \mathrm{~F}$ & Terbaca & Ruang tamu \\
4 & $110008368 \mathrm{DA} 2$ & Tidak terbaca & Dapur \\
5 & $1100080 \mathrm{AA3B} 0$ & Terbaca & Ruang tamu \\
6 & $1100083 \mathrm{~A} 1 \mathrm{C} 3$ & Terbaca & Kamar \\
7 & $110008368 \mathrm{DA} 2$ & Terbaca & Kamar \\
8 & $1100080 \mathrm{AA} 3 \mathrm{~B} 0$ & Terbaca & Kamar \\
9 & $1100083 \mathrm{~A} 1 \mathrm{C} 3 \mathrm{~F}$ & Tidak terbaca & Kamar \\
10 & $1100080 \mathrm{~A} 2330$ & Tidak terbaca & Dapur \\
\hline \hline
\end{tabular}

Tabel 1 menunjukan beberapa RFID reader gagal membaca lokasi yang sesuai dengan informasi yang seharusnya, dengan tingkat keberhasilan dari 10 kali pengujian sebesar 70\%. Hal ini dikarenakan posisi berjalan penderita autis yang cenderung tidak sama saat memasuki ruangan. Sehingga tag RFID yang bersifat pasif tidak bisa terbaca oleh reader.

\section{KESIMPULAN DAN SARAN}

Berdasarkan hasil pengujian, pengolahan data dan analisa data maka dapat ditarik kesimpulan sebagai berikut:

1. Posisi penderita autism dapat diketahui sesuai dengan hasil pembacaan tag oleh masing-masing RFID reader.
2. Pengujian pembacaan RFID tag didapatkan hasil bahwa RFID Reader frekuensi $125 \mathrm{khz}$ tidak mampu membaca tag saat penderita berjalan memasuki ruangan dengan posisi tag tidak tepat di depan reader.

3. Implementasi sistem context-aware berdasarkan lokasi dapat memberikan informasi berdasarkan kebutuhan sistem pada tiap-tiap ruangan yang ditandai.

Beberapa saran untuk pengembangan penelitian selanjutnya dapat berupa:

1. Menggunakan tag aktif yang dapat dibaca oleh reader dengan jangkauan yang lebih besar.

2. Sistem context-aware yang dirancang sebaiknya juga digabungkan dengan sistem otomatisasi yang terintegrasi dengan teknologi smart home.

\section{REFERENSI}

Dey, A. K., \& Abowd, G. D. (1999). Towards a Better Understanding of Context and ContextAwareness. Computing Systems, 40(3), 304307. https://doi.org/10.1007/3-540-48157-5_29

Emulation, M. (2010). RFID Starter Kit, 232. Retrieved from http://www.innovativeelectronics.com/innovativ e_electronics/download_files/manual/RFID_SK .pdf

Helmeste, M. (2016). Passive RFID sensors. Small.

Khan, M. A., Sharma, M., \& Prabhu, B. (2009). A Survey of RFID Tags. International Journal of Recent Trends in Engineering, 1(4).

Maljaars, J., Boonen, H., Lambrechts, G., Van Leeuwen, K., \& Noens, I. (2014). Maternal parenting behavior and child behavior problems in families of children and adolescents with autism spectrum disorder. Journal of Autism and Developmental Disorders. https://doi.org/10.1007/s10803-013-1894-8

Maynord, M. (2014). Context-Aware Systems.

Ratajczak, H. V. (2011). Theoretical aspects of autism: causes--a review. Journal of Immunotoxicology, $\quad 8(1), \quad 68-79$. https://doi.org/10.3109/1547691X.2010.545086

Rivero-Rodriguez, A., Pileggi, P., \& Nykänen, O. A. (2016). Mobile Context-Aware Systems: Technologies, Resources and Applications. 
International Journal of Interactive Mobile Technologies (iJIM). https://doi.org/10.3991/ijim.v10i2.5367

Teicholz, E., \& Williams, G. (2013). Radio Frequency Identification. In Technology for Facility Managers. https://doi.org/10.1007/978-3-83489728-2_2

Ting, S. L., Kwok, S. K., Tsang, A. H. C., \& Ho, G. T. S. (2011). The Study on Using Passive RFID Tags for Indoor Positioning. International Journal of Engineering Business Management, $3(1), 9-15$. 